\title{
Effect of volatile compounds in grass silage on voluntary intake by growing cattle
}

\author{
S. J. Krizsan ${ }^{1 \dagger}$, F. Westad², T. Ådnøy ${ }^{1}$, E. Odden³ , S. E. Aakre ${ }^{4}$ and Å. T. Randby ${ }^{1}$
}

\begin{abstract}
${ }^{1}$ Department of Animal and Aquacultural Sciences, Norwegian University of Life Sciences, PO Box 5003, N-1432Ås, Norway; ${ }^{2}$ Norwegian Food Research Institute, Osloveien 1, N-1430Ås, Norway; ${ }^{3}$ Pronova Biocare, PO Box 2109, N-3202 Sandefjord, Norway; ${ }^{4}$ Department of Laboratory Medicine, Telemark Hospital, N-3910 Skien, Norway
\end{abstract}

(Received 16 May 2006; Accepted 24 September 2006)

\begin{abstract}
Twenty-four low dry matter (DM) silages differing in fermentation quality were harvested at the same time from a crop that consisted mainly of timothy (Phleum pratense), and meadow fescue (Festuca pratensis). The silage samples were analysed by gas chromatography (GC) - mass spectrometry and gas chromatography - flame ionisation detection in order to determine and quantify volatiles present in silage. The voluntary intake of the 24 silages had been measured in a previous feeding trial with growing steers of Norwegian Red. Thirteen esters, five aldehydes, three alcohols, and one sulphide were identified and quantified. A total of 51 variables describing the chemical composition of the silages were included in a partial least-squares regression, and the relationship of silage fermentation quality to voluntary intake was elucidated. The importance of variables describing silage fermentation quality in relation to intake was judged from a best combination procedure, jack-knifing, and empirical correlations of the variables to intake. The GC-analysed compounds were mainly present in poorly fermented silages. However, compared with other explanatory chemical variables none of these compounds was of importance for the voluntary intake as evaluated by partial least-squares regression. A validated variance of $71 \%$ in silage DM intake was explained with the selected variables: total acids (TA), total volatile fatty acids (TVFA), lactic acid/total acid ratio and propionic acid. In this study extent (by the variable TA) and type of silage fermentation (by TVFA) influenced intake. Further, it is suggested that by restricting the fermentation in low DM grass silages the potential intake of silage DM is maximised.
\end{abstract}

Keywords: fermentation, silage, volatile compounds, voluntary intake.

\section{Introduction}

Grass silage is the dominating feed in ruminant production systems in Norway. Food intake is the most important factor in explaining nutrient supply and animal performance of dairy cows (Huhtanen, 2003). There are primarily economic reasons for optimising dry-matter intake (DMI) from grass silage. Intake of forages is limited by the interplay between the energy demand of the animal and the bulk of the diet (Mertens, 1994). Huhtanen et al. (2002) presented a hypothetical model for intake of grass silages differing in digestibility and fermentation quality. In this model, intake of good quality silage is not restricted by fermentation. The first level of constraint is explained by increased silage fermentation and imbalanced supply of absorbed nutrients. A further reduction in intake is stipulated as a consequence of palatability. Mertens (1994) suggested that psychogenic modifiers can impact both short- and long-term intake, and

\footnotetext{
${ }^{\dagger}$ E-mail: sophie.krizsan@umb.no
}

that palatability is the most common feed characteristic among these modifiers. Fermentation end products in silage have long been believed to impact silage intake through an effect of palatability.

Ensilage is a complex process and a vast number of compounds are generated as a consequence of fermentation. Mo et al. (2001) reported 51 fermentation products in collected field samples of grass silage. The majority of these compounds were esters. Carbonyl compounds have also been detected in silage with reference to their potential toxicity (Langin et al., 1989). Carbonyl compounds, alcohols, esters, and short-chain fatty acids are known as flavour volatiles in fermented beverages and food (Henk, 1991). In predictions of silage dry-matter intake (SDMI), several authors have traditionally used simple and multiple linear least-squares regression analyses of silage constituents (Rook and Gill, 1990; Steen et al., 1998; Huhtanen et al., 2002; Krizsan and Randby, 2006). Quality parameters in silage are often inter-correlated. Partial least-squares 
regression (PLSR) analysis is able to handle a larger number of variables, can deal with collinearity, and present graphics giving interpretational advantage in terms of the underlying biological processes (Martens and Martens, 2001).

In this study 24 silage samples differing in fermentation quality were analysed by gas chromatography - mass spectrometry (GC-MS) and gas chromatography - flame ionisation detection (GC-FID) to determine and quantify volatile silage compounds in addition to more commonly analysed chemical substances. The objective was to relate silage components to intake, find the most descriptive variables, and elucidate the importance of a wide variety of fermentation end products on the voluntary intake of grass silage.

\section{Material and methods}

\section{Silage samples and intake data}

The silage samples subjected to the GC analyses were from 24 silages produced at Hellerud Research Station in Norway $\left(60^{\circ} \mathrm{N}, 11^{\circ} \mathrm{E}\right)$ in early June 2002 . The silages were harvested from the same sward (>80\% Phleum pratense) within $60 \mathrm{~h}$. Harvesters, additives, application rate within additive and the storage structure were varied to induce variation in fermentation quality. The voluntary intake of the silages was determined with growing steers in a previous feeding trial (Krizsan and Randby, 2006). Five forages were offered at a time in each of totally five periods. The periods consisted of 2 weeks of feeding the same standard silage, followed by 3 weeks feeding experimental feed. The 2-week feeding periods with standard silage removed possible carry-over effects and were used as covariate in the statistical analysis to correct for variation due to animal (Abrams et al., 1987). Silage was fed as the sole food but supplemented with a commercial mineral/vitamin mixture. Detailed information about the preparation of the silages and the experimental design has been given in Krizsan and Randby (2006).

Samples were collected 3 days/week in the previous feeding trial. Feed samples were stored in a freezer at $-20^{\circ} \mathrm{C}$ immediately after collection. At the end of the experiment dry and fresh weekly composite samples were made. Dry samples were made by oven-drying for $24 \mathrm{~h}$ in $67^{\circ} \mathrm{C}$, thereafter equilibrated to room humidity for $24 \mathrm{~h}$ and kept in a dark storage room at an average temperature below $20^{\circ} \mathrm{C}$. Fresh samples were further stored in the freezer until analysis or directly subjected to analysis. Dried composite samples had previously been analysed for neutral-detergent fibre (NDF), acid-detergent fibre (ADF), acid-detergent lignin (ADL), acid-detergent insoluble nitrogen (ADIN), DM, ash, ether extract, total N (TN), non-protein nitrogen (NPN), true soluble protein (TSP), and organic matter degradability (OMD) (by analysing NDF residues of the samples for ash content before and after an $72 \mathrm{~h}$ in vitro gas production incubation). Extracts from the fresh composite silage samples was at the same time analysed for water-soluble carbohydrate (WSC), pH, formic acid, acetic acid, propionic acid, butyric acid, lactic acid, ethanol, $\mathrm{NH}_{3}-\mathrm{N}$, TN and the amines: 2-phenyl-ethylamine, histamine, tryptamine, tyramine, putrescine, and cadaverine. The amines were determined by capillary zone electrophoresis (P/ACE ${ }^{\mathrm{TM}} \mathrm{MDQ}$ system (Beckman Coulter, Inc., Fullerton, CA, USA)) with UV spectrophotometer for detection. Putrescine and cadaverine were analysed by the indirect UV-method with Waters UVKat-3 (Waters Corp., Milford, MA, USA) as electrolyte. Acetic acid, propionic acid and butyric acid were also expressed as a sum of total volatile fatty acids (TVFA).

Oven DM contents of grass silage were corrected for volatile losses by the addition of $80 \%$ of the measured concentrations of formic, acetic, propionic, and butyric acid and $100 \%$ of the ethanol measured in wet samples to the DM contents determined by oven-drying (Nørgaard Pedersen, 1967; Mo and Tjørnholm, 1978). Correction of $\mathrm{NH}_{3}-\mathrm{N}$ values and crude protein $(\mathrm{CP})(\mathrm{TN} \times 6.25)$ values had been applied for silages treated with $\mathrm{NH}_{3}$-containing additives. The corrections were done on a wet weight basis, subtracting $80 \%$ of the applied $\mathrm{N}$ (assumed $20 \%$ field losses) from the $\mathrm{NH}_{3}-\mathrm{N}$ and TN determinations. All chemical analyses from previous feeding trial are presented in Table 1. Further description of chemical analyses and detailed information of composition of each of the silages have been presented in Krizsan and Randby (2006).

\section{Chemical analysis}

Identification of volatile substances was performed with GC-MS and quantification of identified substances was enabled with GC-FID. Approximately 2.5 to $5.0 \mathrm{~g}$ of the thawed samples of silage and herbage material was weighed into $20 \mathrm{ml}$ gas-tight headspace flasks. The flasks were incubated at $60^{\circ} \mathrm{C}$ for $60 \mathrm{~min}$ prior to analysis. The chromatographic techniques used static headspace sample introduction, and $1.0 \mathrm{ml}$ of the headspace was transferred to the GC. The GC-MS analysis was performed with a CE 8000 Top GC equipped with a Finnigan Voyager single stage quadrupole $M S$ in the energy of ionisation of $70 \mathrm{eV}$ (Thermo Electron Corp., San Jose, CA, USA). A HewlettPackard fused-silica column $60 \mathrm{~m}$ long, $0.25 \mathrm{~mm}$ internal diameter, and $0.5 \mu \mathrm{m}$ film thickness, HP-Innowax (Crosslinked polyethylene glycol, $\mathrm{p} / \mathrm{n} 19091 \mathrm{~N}-236$ ) was used. The inlet temperature was set to $240^{\circ} \mathrm{C}$, and split mode injection (split vent; approx. $20 \mathrm{ml} / \mathrm{min}$ ) was performed during injection. GC-FID analyses were performed with a CE 8000 Top GC equipped with an automatic headspace sampler, and a FID (Thermo Electron Corp., San Jose, CA, USA). A Hewlett Packard fused-silica column $60 \mathrm{~m}$ long, $0.32 \mathrm{~mm}$ internal diameter, and $0.5 \mu \mathrm{m}$ film thickness, HP-Innowax (cross-linked polyethylene glycol, p/n $19091 \mathrm{~N}-216$ (Agilent Technologies, Santa Clara, CA, USA)) was used. For both GC-MS and GC-FID analyses, the carrier gas was helium with a flow rate of $1.0 \mathrm{ml} / \mathrm{min}$, linear velocity of $21.4 \mathrm{~cm} / \mathrm{s}$, and a pressure of $77 \mathrm{kPa}$ (GC-FID) at $40^{\circ} \mathrm{C}$, in constant pressure mode. In the GC-MS system, column pressure was reduced to retain GC-FID linear velocity. The column 
Table 1 Chemical composition of the 24 silages (content in silages given as mean and range) and the initial herbage $(n=2)$ in $g / k g d r y$ matter unless otherwise stated

\begin{tabular}{|c|c|c|c|c|c|}
\hline & Mean & Minimum & Maximum & S.D. & Herbage \\
\hline DM (g/kg) & 213 & 166 & 237 & 17.6 & 207 \\
\hline $\mathrm{OMD}^{\dagger}$ & 804 & 787 & 822 & 8.53 & $N A^{\S}$ \\
\hline Crude protein ${ }^{\ddagger}$ & 174 & 163 & 193 & 8.69 & 184 \\
\hline NDF & 544 & 476 & 601 & 33.5 & 582 \\
\hline ADF & 348 & 325 & 383 & 15.0 & 313 \\
\hline ADL & 40.1 & 28.2 & 63.9 & 8.27 & 43.2 \\
\hline $\mathrm{OM}$ & 916 & 902 & 930 & 6.29 & 918 \\
\hline Ether extract & 25.3 & 19.9 & 32.0 & 2.84 & 20.2 \\
\hline WSC & 33.0 & 16.3 & 70.9 & 15.3 & 95.3 \\
\hline Ethanol & 6.8 & 3.4 & 13.2 & 2.40 & 2.0 \\
\hline $\mathrm{pH}$ & 4.56 & 4.01 & 5.26 & 0.338 & NA \\
\hline Formic acid & 2.6 & 0.0 & 12.7 & 3.53 & 2.0 \\
\hline Acetic acid & 28.6 & 11.5 & 64.7 & 14.6 & 2.2 \\
\hline Propionic acid & 1.0 & 0.0 & 5.2 & 1.61 & 0.0 \\
\hline Butyric acid & 6.0 & 0.0 & 25.1 & 8.31 & 0.0 \\
\hline Total VFA & 35.5 & 11.5 & 85.8 & 22.1 & 2.2 \\
\hline Lactic acid (LA) & 49.3 & 2.2 & 102 & 23.8 & 1.5 \\
\hline Total acids (TA) & 84.9 & 48.3 & 142 & 20.1 & 3.7 \\
\hline LA/TA & 0.584 & 0.025 & 0.827 & 0.235 & 0.402 \\
\hline NPN (g/kg TN) & 605 & 461 & 719 & 70.5 & NA \\
\hline TSP (g/kg TN) & 37.0 & 4.00 & 75.2 & 17.5 & NA \\
\hline ADIN (g/kg TN) & 18.9 & 12.2 & 28.9 & 4.90 & 11.1 \\
\hline $\mathrm{NH}_{3}-\mathrm{N}^{\ddagger}(\mathrm{g} / \mathrm{kg} \mathrm{TN})$ & 142 & 62 & 255 & 41.5 & 36.4 \\
\hline 2-phenyl-ethylamine & 0.101 & 0.00 & 0.257 & 0.083 & 0.0 \\
\hline Histamine & 0.347 & 0.00 & 1.43 & 0.396 & 0.0 \\
\hline Tryptamine & 0.085 & 0.00 & 0.643 & 0.151 & 0.0 \\
\hline Tyramine & 1.49 & 0.294 & 2.68 & 0.650 & 0.02 \\
\hline Putrescine & 1.44 & 0.174 & 3.73 & 0.897 & 0.06 \\
\hline Cadaverine & 1.36 & 0.122 & 5.41 & 1.34 & 0.03 \\
\hline Total amines & 4.82 & 0.975 & 10.1 & 3.21 & 0.11 \\
\hline
\end{tabular}

${ }^{\dagger}$ The organic matter degradability was determined from the ash content after in vitro gas incubation for $72 \mathrm{~h}$.

${ }^{\ddagger}$ Corrected for additive-derived nitrogen.

${ }^{\S} \mathrm{NA}=$ not analysed.

temperature was held initially at $40^{\circ} \mathrm{C}$ for $1 \mathrm{~min}$, increased to $60^{\circ} \mathrm{C}$ at $5.0^{\circ} \mathrm{C} / \mathrm{min}$, then isothermal at $60^{\circ} \mathrm{C}$ for $10 \mathrm{~min}$, further increased to $200^{\circ} \mathrm{C}$ at $10.0^{\circ} \mathrm{C} / \mathrm{min}$, and held there for $15 \mathrm{~min}$. The GC-MS analysis was performed in full scan acquisition mode, and the scans were recorded as positive ions in the range of 20 to $400 \mathrm{amu}$. Scan rate was 1 scan per s. The compounds were identified with Mass Spectral Library (Xcalibur NIST 98/EPA/NIH). Quantification was performed by an external standard technique, which implies a development of separate calibration curves of each component. Standards were not produced in the similar silage matrix as the samples. In addition to the feed samples, duplicate herbage samples were analysed by GC-FID. The duplicate herbage samples were composites of samples taken before ensiling from all silages.

\section{Statistical analysis}

The relationship between feed intake and chemical components of the silages was examined with PLSR in
Unscrambler (Version 8.0.5 ${ }^{\circledR}$ Camo, Oslo, Norway). Prior to the PLSR analysis all variables were standardised to a mean of zero and divided by their total initial standard deviation (each variable was given a total initial standard deviation of one) (Martens and Martens, 2001). Cross-validation (CV) was applied to determine the optimal number of principal components (PC) in the model. The optimal number of PCs was defined at minimum prediction error, expressed as cross-validated root mean-square error (RMSECV) in $y$ (intake of silages in $\mathrm{kg} \mathrm{DM}$ per $100 \mathrm{~kg}$ body weight). Likewise, the calibration fits were evaluated by the root mean square error (RMSEC). Correlations of each explanatory variable to intake with corresponding $P$-values were calculated. Uncertainties of the loadings were estimated with jack-knifing (JK) to identify not significant variables in the PCs (Martens and Martens, 2000). The JK variable selection was evaluated with a best combination procedure. The search started with a combination of the five most significant variables of a subset of the 25 best variables as evaluated with JK. If no reduction in the RMSECV was reached after 1000 new combinations the run was aborted. In addition to CV cross model validation (CMV) was used to assess the stability and predictive ability of the model (Hjorth, 1994). The cross model validated root meansquare error (RMSECMV) was used to express a conservative estimate of the predictive ability of the model. Due to the limited number of samples leave-one-out validation was performed for both CV and CMV. Variables not included in the final model were made passive (scaled by a factor of $10^{-5}$ ). Thereby, these variables could be viewed with the selected variables without affecting the model.

\section{Results}

Silage composition and intake data

The average intake of the 24 silages was $2.38 \pm 0.196 \mathrm{~kg}$ DM per $100 \mathrm{~kg}$ body weight (BW) with a range from 1.79 to $2.65 \mathrm{~kg}$ DM per $100 \mathrm{~kg}$ BW. A total of 13 esters, five aldehydes, three alcohols, and one sulphide were identified and quantified. For the 24 silages the total quantity of GCanalysed compounds ranged between 44 and $533 \mathrm{mg} / \mathrm{kg}$ DM with a mean value of $173 \mathrm{mg} / \mathrm{kg}$ DM. The average distribution between esters, aldehydes, and alcohols of the total quantity was: 35,14 , and $51 \%$, respectively. All chemical components found in the silage samples are listed in order of retention time for both GC-MS and GC-FID in Table 2. The means and ranges of the quantified chemical components in the silages and in the initial herbage are also presented in Table 2 . The relevance for quantifying and including identified components in the modelling of the silage intake was determined from the number of samples in which they were represented: the component was excluded from statistical analysis if it was found in fewer than six silage samples or fewer than three duplicate silage samples. A causal relationship between the measured variable and silage intake was then judged as not relevant. Rejected components were: 2-methyl-ethyl 
Krizsan, Westad, Ådnøy, Odden, Aakre and Randby

Table 2 Content of GC analysed compounds, listed in order of retention time (RT) (min) for GC-MS and GC-FID, in the 24 silages (given as mean and range) and average $(n=2)$ detected concentrations in the initial herbage $(\mathrm{mg} / \mathrm{kg} \text { dry matter })^{t}$

\begin{tabular}{lccccccc}
\hline \hline & Mean & Minimum & Maximum & S.D. & Herbage & RT: GC-MS & RT: GC-FID \\
\hline Ethanal & 2.67 & 0.00 & 6.14 & 1.70 & 3.33 & 5.68 & 6.42 \\
Dimethyl sulphide & 1.82 & 0.653 & 4.57 & 1.08 & 1.68 & 6.34 & 7.52 \\
Propanal & 0.263 & 0.00 & 2.53 & 0.577 & 0.889 & 7.10 & 7.87 \\
2-methyl propanal & 4.96 & 1.19 & 10.4 & 2.30 & 2.20 & 7.52 & 8.19 \\
Methyl ethanoate & 1.09 & 0.00 & 2.11 & 0.641 & 0.00 & 7.89 & 9.59 \\
Ethyl ethanoate & 6.95 & 1.53 & 13.7 & 3.42 & 1.11 & 9.58 & 10.18 \\
Methanol & 22.6 & 9.61 & 32.2 & 6.65 & 20.7 & 9.80 & 10.40 \\
2-methyl butanal & 6.09 & 1.08 & 12.5 & 3.10 & 1.70 & 10.70 & 11.25 \\
3-methyl butanal & 9.97 & 2.97 & 20.9 & 4.69 & 3.14 & 10.85 & 11.42 \\
Ethyl propanoate & 0.912 & 0.00 & 5.36 & 1.18 & 0.00 & 12.70 & 13.22 \\
Propyl ethanoate & 4.03 & 0.00 & 45.4 & 9.69 & 0.00 & 13.67 & 14.19 \\
Methyl butanoate & 1.35 & 0.00 & 7.29 & 2.22 & 0.00 & 14.39 & 14.89 \\
2-Butanol & 18.4 & 1.78 & 84.3 & 20.8 & 0.00 & 16.52 & 16.75 \\
1-Propanol & 46.3 & 3.84 & 361 & 83.6 & 0.00 & 17.41 & 17.52 \\
Ethyl butanoate & 25.8 & 0.00 & 200 & 52.6 & 0.00 & 17.50 & 17.66 \\
Butyl ethanoate & 0.531 & 0.00 & 6.78 & 1.53 & 0.00 & 19.16 & 19.33 \\
Methyl pentanoate & 1.23 & 0.00 & 16.2 & 3.26 & 0.00 & 19.82 & 19.97 \\
Propyl butanoate & 9.15 & 0.00 & 90.6 & 20.9 & 0.00 & 21.25 & 21.42 \\
Ethyl pentanoate & 2.32 & 0.00 & 21.1 & 4.75 & 0.00 & 21.71 & 21.89 \\
Methyl hexanoate & 0.346 & 0.00 & 5.72 & 1.19 & 0.00 & 23.54 & 23.79 \\
Butyl butanoate & 3.37 & 0.00 & 39.9 & 8.77 & 0.00 & 24.45 & 24.75 \\
Ethyl hexanoate & 2.68 & 0.00 & 37.2 & 7.65 & 0.00 & 24.89 & 25.21 \\
\hline \hline
\end{tabular}

${ }^{\dagger}$ Silage and herbage samples stored in freezer $\left(-20^{\circ} \mathrm{C}\right)$, thawed and incubated in headspace flasks at $60^{\circ} \mathrm{C}$ for $1 \mathrm{~h}$ prior to the analysis.

propanoate, propyl pentanoate, propyl hexanoate, butyl hexanoate, 2-methyl propanoate, 3-methyl butanoate, pentanoic acid, and hexanoic acid. Butyl butanoate and 1-methyl-propyl butanoate were not separated in the GCMS chromatogram. Standards for these two components were problematic to purchase, therefore they were quantified as one single component by using calibration information from the ethyl hexanoate peak.

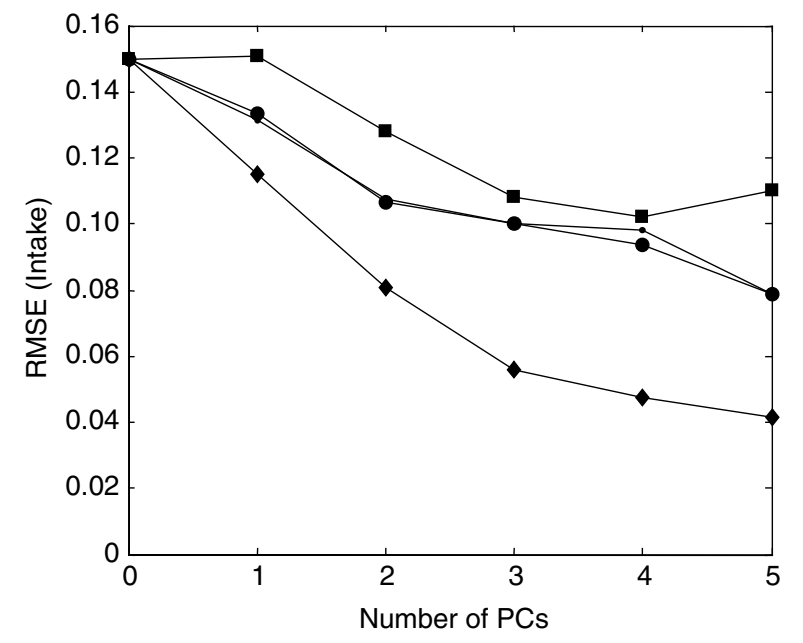

Figure 1 Root mean-square error (RMSE) of silage intake (kg dry matter per $100 \mathrm{~kg}$ live weight) at five principal components (PCS) for the calibration model including all 51 variables (diamonds), the cross validated model with all 51 variables (squares), the cross validated model with five selected variables (large circles), and the cross model validated 5-variable model (small circles).

\section{Principal explanatory components}

Root mean-square error of silage intake at different numbers of PCs for the calibration model including all 51 variables, the cross validated model with all 51 variables, the cross validated model with five selected variables, and the cross model validated five-variable model are shown in Figure 1. There was a minimum of the cross-validated estimate of RMSE in the curve for the full model at four PC $($ RMSECV $=0.114)$. The corresponding calibration RMSE was 0.050 of all variables in a four-component PLSR model. The correlation between each silage component and intake, the significance level of the correlation, and the significance level for each variable from the uncertainty test on the four-component PLSR model are listed in Table 3. The variables NDF, TVFA, TA, methanol, and 1-propanol had significance levels (JK) less than 0.05. Other variables close to significance as evaluated by JK were ADL $\quad(P=0.065), \quad p H \quad(P=0.072), \quad$ AcA $\quad(P=0.073)$, PA $(P=0.111), L A / T A \quad(P=0.120)$, methyl ethanoate $(P=0.085)$, ethyl ethanoate $(P=0.090), 2$-methyl butanal $(P=0.130)$, and ethyl propanoate $(P=0.055)$. For $A c A$, PA, TVFA, TA, LA/TA ratio, methyl ethanoate, and 1-propanol, a small P-value from the uncertainty test coincided with a significant empirical correlation.

With outlier detection by Hotelling T2-statistics (Edward, 2003) in Figure 2, where the Hotelling T2-value for each sample is plotted against the sample number after three PLSR components, and with the critical test value (at $\alpha=0.05$ ) indicated as a horizontal line, sample 6 was tagged as an outlier. After four PLSR components the 
Table 3 Correlation between the different silage components and intake $(r)$, significance of $r$, and significance from the uncertainty test estimated with jack-knifing (JK)

\begin{tabular}{|c|c|c|c|c|}
\hline No. & Component & $r$ & $\begin{array}{c}\text { Significance } \\
\text { of } r\end{array}$ & $\begin{array}{c}\text { Significance } \\
\text { of JK }\end{array}$ \\
\hline 1 & DM & 0.630 & 0.001 & 0.701 \\
\hline 2 & OMD & 0.257 & 0.226 & 0.593 \\
\hline 3 & Crude protein & -0.322 & 0.125 & 0.940 \\
\hline 4 & NDF & 0.200 & 0.349 & 0.042 \\
\hline 5 & ADF & -0.332 & 0.113 & 0.325 \\
\hline 6 & ADL & -0.237 & 0.264 & 0.065 \\
\hline 7 & $\mathrm{OM}$ & 0.071 & 0.743 & 0.323 \\
\hline 8 & Ether extract & -0.244 & 0.250 & 0.693 \\
\hline 9 & WSC & 0.279 & 0.186 & 0.240 \\
\hline 10 & Ethanol & -0.288 & 0.172 & 0.629 \\
\hline 11 & $\mathrm{PH}$ & -0.037 & 0.865 & 0.072 \\
\hline 12 & Acetic acid & -0.642 & 0.001 & 0.073 \\
\hline 13 & Propionic acid & -0.740 & 0.000 & 0.111 \\
\hline 14 & Butyric acid & -0.430 & 0.036 & 0.799 \\
\hline 15 & Total VFA & -0.639 & 0.001 & 0.013 \\
\hline 16 & Lactic acid (LA) & 0.125 & 0.562 & 0.175 \\
\hline 17 & Total acids (TA) & -0.553 & 0.005 & 0.001 \\
\hline 18 & LA/TA & 0.495 & 0.014 & 0.120 \\
\hline 19 & Non-protein N & 0.249 & 0.241 & 0.498 \\
\hline 20 & True soluble protein & -0.003 & 0.991 & 0.718 \\
\hline 21 & ADIN & -0.433 & 0.035 & 0.498 \\
\hline 22 & $\mathrm{NH}_{3}-\mathrm{N}$ & -0.373 & 0.073 & 0.213 \\
\hline 23 & 2-phenyl-ethylamine & -0.207 & 0.332 & 0.879 \\
\hline 24 & Histamine & -0.529 & 0.008 & 0.245 \\
\hline 25 & Tryptamine & -0.677 & 0.000 & 0.663 \\
\hline 26 & Tyramine & -0.331 & 0.114 & 0.494 \\
\hline 27 & Putrescine & -0.242 & 0.255 & 0.286 \\
\hline 28 & Cadaverine & -0.476 & 0.019 & 0.347 \\
\hline 29 & Total amines & -0.436 & 0.033 & 0.766 \\
\hline 30 & Ethanal & -0.198 & 0.354 & 0.320 \\
\hline 31 & Dimethyl sulphide & 0.171 & 0.423 & 0.172 \\
\hline 32 & Propanal & -0.356 & 0.088 & 0.523 \\
\hline 33 & 2-methyl propanal & -0.084 & 0.698 & 0.743 \\
\hline 34 & Methyl ethanoate & 0.453 & 0.026 & 0.085 \\
\hline 35 & Ethyl ethanoate & 0.281 & 0.183 & 0.090 \\
\hline 36 & Methanol & -0.301 & 0.154 & 0.012 \\
\hline 37 & 2-methyl butanal & -0.070 & 0.746 & 0.130 \\
\hline 38 & 3-methyl butanal & 0.016 & 0.940 & 0.209 \\
\hline 39 & Ethyl propanoate & -0.084 & 0.698 & 0.055 \\
\hline 40 & Propyl ethanoate & -0.222 & 0.296 & 0.834 \\
\hline 41 & Methyl butanoate & -0.055 & 0.800 & 0.889 \\
\hline 42 & 2-Butanol & -0.007 & 0.972 & 0.352 \\
\hline 43 & 1-Propanol & -0.448 & 0.028 & 0.005 \\
\hline 44 & Ethyl butanoate & -0.007 & 0.975 & 0.724 \\
\hline 45 & Butyl ethanoate & -0.596 & 0.002 & 0.159 \\
\hline 46 & Methyl pentanoate & -0.177 & 0.408 & 0.465 \\
\hline 47 & Propyl butanoate & -0.315 & 0.134 & 0.689 \\
\hline 48 & Ethyl pentanoate & -0.599 & 0.002 & 0.776 \\
\hline 49 & Methyl hexanoate & -0.651 & 0.001 & 0.327 \\
\hline 50 & Butyl butanoate & -0.583 & 0.003 & 0.977 \\
\hline 51 & Ethyl hexanoate & -0.633 & 0.001 & 0.575 \\
\hline
\end{tabular}

T2-value for sample 6 is slightly below the critical test value at $\alpha=0.05$ (13.6 v. 13.7). Silage sample 6 was considered an outlier and removed in further modelling.
The input data was reduced to five explanatory variables, chosen after a best combination search among the most significant variables. The best combination procedure gave an RMSEC of 0.062 and an RMSECV of 0.079 for the combination PA, TVFA, TA, LA/TA, and putrescine after five PCs (Figure 1). Root mean-square errors for the CMV procedure for the five-variable five-component model are presented in Figure 1. The frequencies of significance from the CMV procedure for the chosen variables were: PA 100\%, TVFA $78 \%$, TA $100 \%$, LA/TA $83 \%$, and putrescine $96 \%$.

The correlation loadings for the five-variable model were transformed to correlation coefficients between the PC and each input variable. The resulting correlation loading plot of $\mathbf{r}_{1}$ (PC1, abscissa) $v$. $\mathbf{r}_{2}$ (PC2, ordinate) is shown in Figure 3. The score plot in Figure 4 for the five-variable model was used to provide information about the sample distribution in this input data. The squared sum of $r_{1}$ and $r_{2}$ represented the relative amount of variance of $y$ explained in Figure 3. The outer dotted ellipse represents $100 \%$ explained variance, and the inner ellipse $50 \%$ explained variance of $y$. To visualize all of the variables in Figures 3 and 5 all except the five selected variables were marked with number according to Table 3 . Thereby, variables made passive did not affect the model, but was still possible to interpret with the others. For interpretation a second correlation loading plot, $\mathbf{r}_{1}$ ( $\mathrm{PC1}$, abscissa) versus $\mathbf{r}_{3}(\mathrm{PC}$, ordinate) were also considered for the five-variable model (Figure 5). PC4 contributed only $1 \%$ to the explained variation in intake, and even less was explained with PC5. The other correlation loading plots were judged not to be of any interpretational interest.

\section{Discussion}

Volatile silage components

The majority of the detected volatile compounds are involved in several biochemical pathways and the

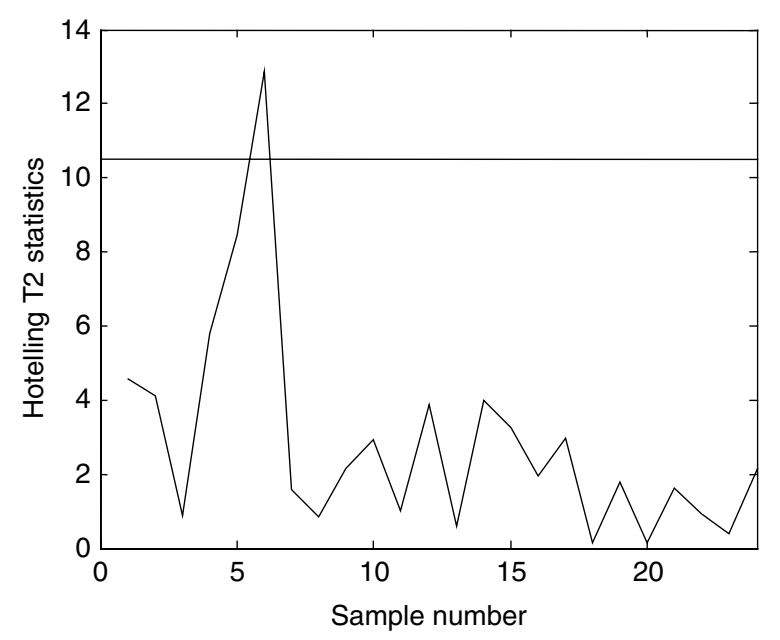

Figure 2 Hotelling T2 statistics for each sample after three PLSR components with critical test value at $\alpha=0.05$ indicated as a horizontal line. 
Krizsan, Westad, Ådnøy, Odden, Aakre and Randby

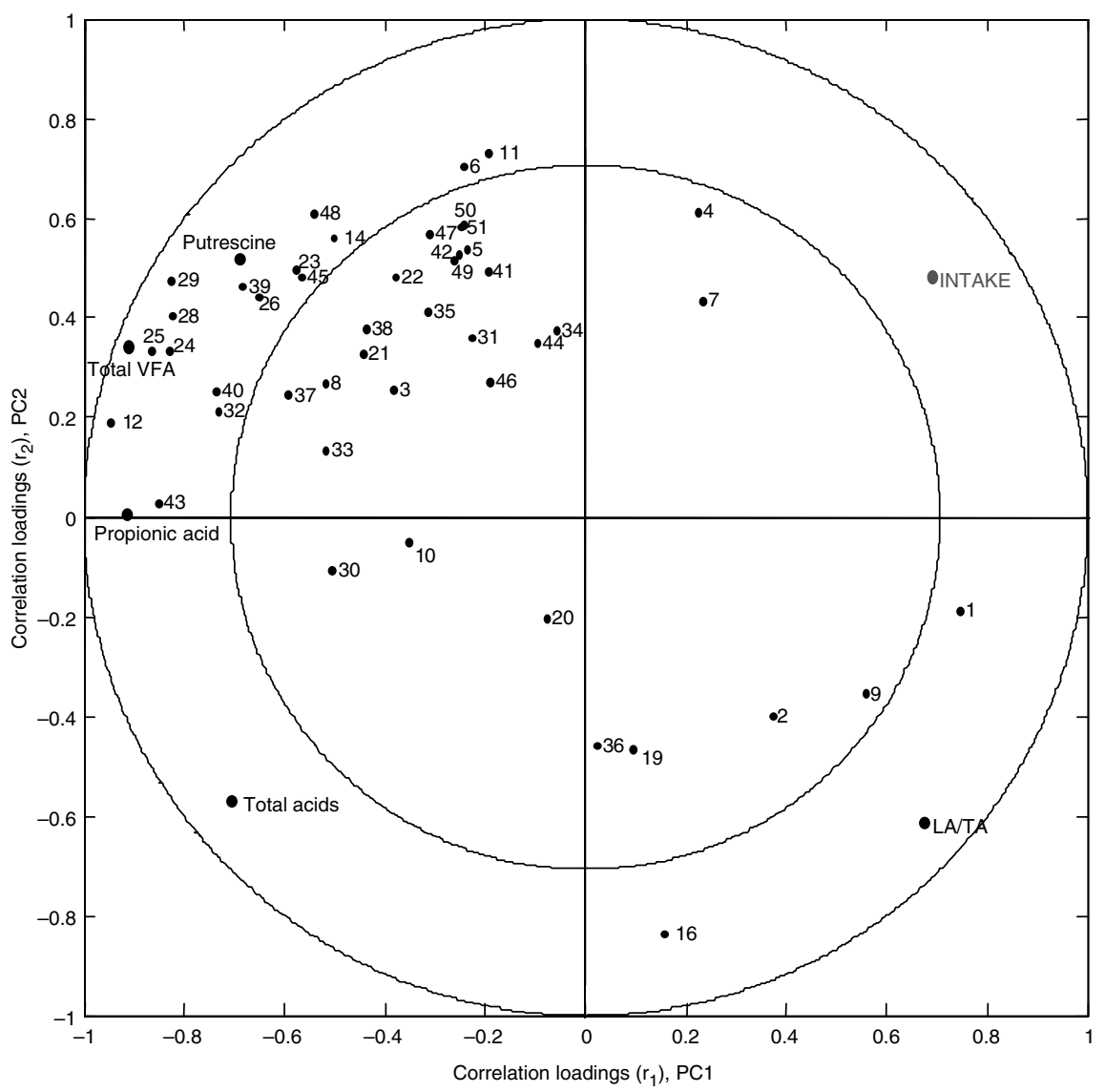

Figure 3 Correlation loading plot of the first two PCs for the five-component model with the five selected variables typed in bold. All other variables treated as passive variables, that is visualised, but without contributing to the explained variance of the response variable (INTAKE).

micro-organisms that are mainly responsible for their formation in silage and expected amounts are not well known. No obvious grouping of the different chemical compounds was evident from Figure 3, and the majority of these volatile compounds were associated with variables

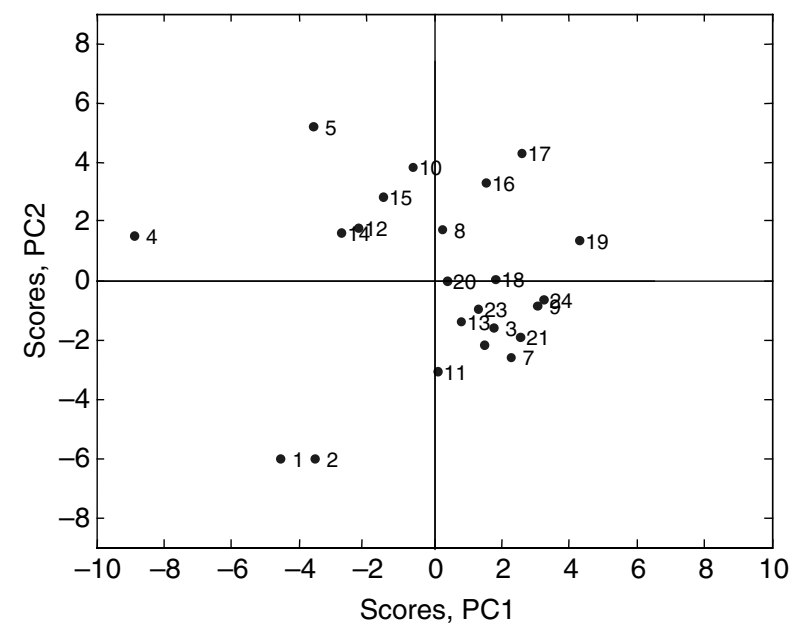

Figure 4 Pattern of relationship between the silage samples in a score plot of PC1 v. PC2 for the five-component model with the five selected variables. usually characterising poor preservation quality (i.e. BA, AcA, and $\mathrm{NH}_{3}-\mathrm{N}$ ) in the north-west quadrant in Figure 3. However, methanol, ethanol, and ethanal were located outside the north-west quadrant. Methanol and ethanal were found in comparable and slightly higher average concentrations, respectively, in the herbage material compared with the silage samples, which indicated that they were not necessarily a consequence of fermentation. Pectin is the major source of methanol in nature, and the breakdown is a result of the activity of pectic enzymes found in plants, bacteria, particularly soil bacteria, yeast, and fungi. In plants they are involved in the growth process, and microbial pectolysis is related to plant pathogenesis or symbiosis (Whitaker, 1990). The average concentration of propanal was also higher in herbage compared with silage. The other detected aldehydes were also present in the herbage, but in lower amounts than the average concentration of the silage samples. The aldehydes ethanal, propanal, butanal, 3-methyl butanal, and pentanal have previously been detected in grass and maize silage (Langin et al., 1989). Butanal and pentanal were not found in the silage samples in the present study, but in addition to the other aldehydes in the study of Langin et al. (1989) 2-methyl propanal and 2-methyl butanal were also detected. The total quantity 
Volatile compounds in grass silage and intake by growing cattle

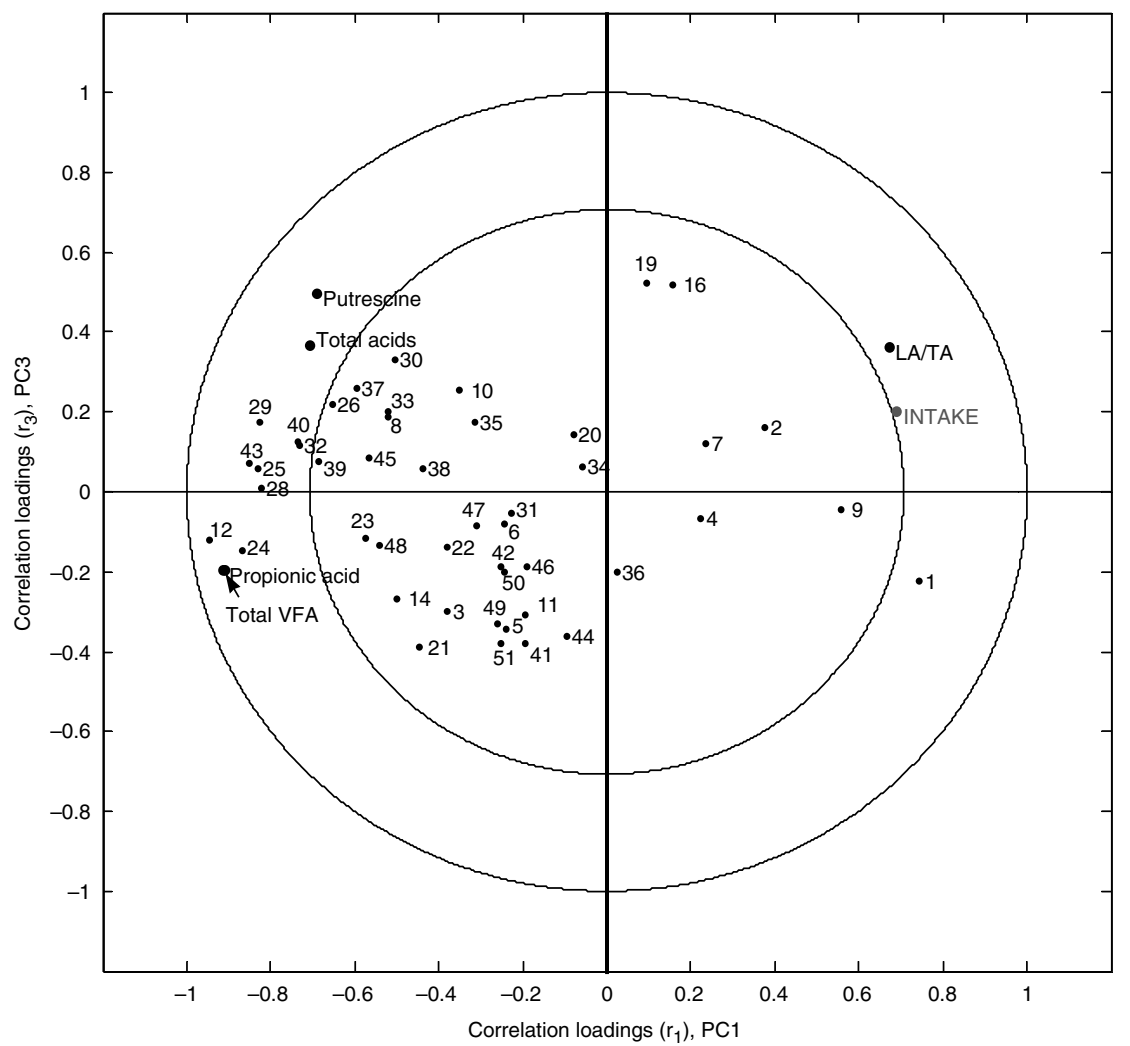

Figure 5 Correlation loading plot of PC1 v. PC3 for the five-component model with the five selected variables (bold), the response variable (INTAKE) and the passive variables.

of carbonyl compounds was ranging from $36 \mathrm{mg} / \mathrm{kg}$ DM to $1535 \mathrm{mg} / \mathrm{kg}$ DM in the study of Langin et al. (1989). The content of carbonyl compounds was much higher in the maize silage than in the grass silage, which could explain the higher detected total concentrations of these minor silage compounds compared with this study. Aldehydes are most commonly recognised as intermediates in the synthesis of alcohols by yeast. Some yeast has an ability to branch carbohydrate metabolism between respiratory and fermentative in an aerobic environment (Käppeli, 1986). Yeasts are found on plants and numbers usually increase after harvest (McDonald et al., 1991). The formation of aldehydes in silage as well as in the herbage material could also be a consequence of oxidation of alcohols. Ethanol was present in low amounts in the harvested grass material (Table 1) in this study. Lees and Jago (1978) pointed out the central role of ethanal in bacterial metabolism of several substrates by lactic acid bacteria, and ethanol was also characterised as a metabolite. There is no clear-cut answer to the origin of ethanal or ethanol in the herbage material in this study. Lactic acid bacteria are present on the standing crop, and will proliferate with the release of cell sap at harvest (McDonald et al., 1991). This could deduce the detected metabolites from lactic acid metabolism in the herbage material. Comparable amounts of dimethyl sulphide were present in the grass material and the silages in this study. Dimethyl sulphide is known as a common flavour compound present in small amounts in milk. It can be formed by either anaerobic or aerobic metabolism of methionine by several micro-organisms (Henk, 1991).

Interpretation of principal components and impact of silage components on intake

More variables were irrelevant in the prediction of intake when evaluated by the JK procedure compared with the calculated empirical correlation coefficients (Table 3). The reason for this could be that some $X$-variables are correlated to other more $y$-relevant $X$-variables, and are thereby given a higher rank when regarded as independent of each other in relation to $y$. The selection of five explanatory variables and removal of sample 6 decreased RMSECV from 0.114 to 0.079 . This corresponded to an improvement from 67 to $75 \%$ of explained CV-variance in $y$. The best combination procedure combined PA, TVFA, TA, LA/TA, and putrescine after five $P C s$. In addition, all of these variables except putrescine were singled out as relevant in relation to silage intake from either empirical correlations or JK. The numerical similarity between RMSECV and RMSECMV for the model, and the high frequencies of significance from the CMV procedure for all variables indicated that the selected set of variables was stable towards keeping objects out. 
No other variables were located in the same quadrant as TA in Figure 3, and intake was located opposed to TA in the north-east direction. Due to the overlapping positioning of sample 1 and 2 in the score plot (Figure 4) these silages were consequently expected to be high in total acid content. The variable TA is regarded as descriptive of the extent rather than the type of fermentation (Huhtanen et al., 2002). Only silage 2 could in fact be characterised as extensively fermented silage with a LA and AcA content of 102 and $35 \mathrm{~g} / \mathrm{kg} \mathrm{DM}$, respectively. The content of LA was moderate $(52 \mathrm{~g} / \mathrm{kg} \mathrm{DM})$ in silage 1 , giving the high TA number in combination with a high concentration of AcA $(55 \mathrm{~g} / \mathrm{kg} \mathrm{DM})$ (Krizsan and Randby, 2006). There is no definitive agreement in the literature that LA per se limits intake. Choung and Chamberlain (1993) reduced silage intake with dietary additions of LA to restrictively fermented silage. Silage pH was very low (3.4) for the highest amount of LA added, and subsequent reduction of ruminal $\mathrm{pH}$ was observed, but not below 6.1. Jaakkola and Huhtanen (1992) did not observe any changes in NDF digestibility with infusions of LA up to $120 \mathrm{~g} / \mathrm{kg}$ DM fed. Among recent research, Dawson and Mayne (1997) did not observe any significant effects on daily DMI when adding levels of LA of 50 and $100 \mathrm{~g} / \mathrm{kg}$ DM silage as fed. However, the basal silage in the study was extensively fermented with $116 \mathrm{~g} \mathrm{LA} / \mathrm{kg}$ DM before the additions.

Tryptamine, cadaverine, and histamine were located close to TVFA in Figure 3. This indicates a positive correlation between those variables when explaining silage intake. Silages $4,5,10,12,14$, and 15 located in the north-west quadrant of Figure 4 were expected to represent low quality silage due to the overlap with the variables in the corresponding quadrant in Figure 3 . The content of $L A, A C A$, and $B A$ for these silages varied between 14 and 51, 23 and 65, and from 11 to $22 \mathrm{~g} / \mathrm{kg}$ DM, respectively. In these silages the total concentrations of GC-analysed esters, aldehydes, and alcohols ranged between 60 and $259 \mathrm{mg} / \mathrm{kg} \mathrm{DM}, 24$ and $50 \mathrm{mg} / \mathrm{kg} \mathrm{DM}$, and from 73 to $405 \mathrm{mg} / \mathrm{kg} \mathrm{DM}$, respectively. In the opposite direction in Figure 4 silages 3, 7, 9, 13, 21, 22, 23 and 24 were expected to represent good quality silages with the analogue positioning of LA/TA in Figure 3. The content of LA in all of these silages was below $66 \mathrm{~g} / \mathrm{kg}$ DM except for silage 22 (with a LA content of $78 \mathrm{~g} / \mathrm{kg} \mathrm{DM}$ ), and the AcA content was below $23 \mathrm{~g} / \mathrm{kg}$ DM. Propionic and butyric acid were only detected in low levels in two separate silages: 0.7 (silage 23) and $1.5 \mathrm{~g} / \mathrm{kg} \mathrm{DM}$ (silage 3), respectively. In these silages the total concentrations of GC-analysed esters, aldehydes, and alcohols ranged between 4 and $12 \mathrm{mg} / \mathrm{kg} \mathrm{DM}, 5$ and $38 \mathrm{mg} / \mathrm{kg} \mathrm{DM}$, and from 31 to $51 \mathrm{mg} / \mathrm{kg} \mathrm{DM}$, respectively. The north-west/south-east direction in Figure 3, when evaluated together with the sample distribution in Figure 4, spanned the contrast between well preserved silages, with a majority of restrictively fermented silages, and silages displaying secondary fermentation (Krizsan and Randby, 2006). The LA/TA ratio is not usually regarded as a good descriptive variable for restrictively fermented silages. The AcA content is generally low in restrictively fermented silages (10 to $15 \mathrm{~g} / \mathrm{kg} \mathrm{DM}$ ), but under certain circumstances, like very high levels of acid applications and/or with wilting, the LA content can also be low (around 20 to $30 \mathrm{~g} / \mathrm{kg} \mathrm{DM}$ ). In this case the LA/TA ratio will not be high. In contrast to this, the LA/TA ratio can be very high for some inoculated silages with similar content of AcA, but considerably higher concentration of LA in the DM (up to $150 \mathrm{~g} / \mathrm{kg} \mathrm{DM}$ ). For this reason LA/TA ratio may be better of indicating silage quality within extensively fermented silages, than when comparing extensively and restrictively fermented silages ( $P$. Huhtanen, personal communication). A low LA/TA ratio could also describe secondarily fermented silage.

A direct negative effect of volatile fatty acids on intake has been established with infusions of the acids in combination rather than when provided individually (Faverdin et al., 1992; Mbanya et al., 1993; Peyraud et al., 1993). In previous studies, restricted lactic acid fermentation has been shown to relate positively to intake, and with increasing extent of lactic acid fermentation intake has been constrained (Rook and Gill, 1990; Huhtanen, 1993; Steen et al., 1998). Intake, as the response variable, was found in the north-east quadrant of Figure 3 and was not directly related to the variables TVFA and LA/TA ratio. However, in Figure 5 representing another dimension, between PC1 and $\mathrm{PC} 3$, intake and LA/TA ratio are located close together, and both opposite to TVFA. This negative relation of TVFA on intake as well as the positive connection between restrictively fermented silages and intake are in agreement with previous surveys.

Putrescine was selected as one of five variables in the best combination search. Close to putrescine in Figure 3 are the variables: total amines, ethyl propanoate, tyramine, and ethyl pentanoate. Butyl ethanoate, 2-phenylethylamine, and butyric acid are also located close to this group. However, these variables are not far from the $50 \%$ explained variance ellipse, and were therefore regarded as less relevant. There is no biological support for separating the variables found in the north-west quadrant around TVFA and putrescine into two groups. Clostridial fermentation characteristics include high TVFA content and considerable amounts of amines (McDonald et al., 1991). Silages 4, 5, 10, 12, 14, and 15 are, in fact, the silages with the highest content of $B A$ and with a total amine content well above the average (except silage 15) (Krizsan and Randby, 2006). Dawson and Mayne (1995, 1996 and 1997) did not achieve any treatment effect of putrescine, either by dietary addition or intraruminal infusion, on DM intake by steers offered grass silage based diets.

The close proximity of PA and 1-propanol in Figure 3 indicate a positive correlation between these variables. Both variables had high negative loadings in PC2, and did contribute to reduced intake in the model. Propionic acid has also previously been pointed out as an important explanatory variable to intake (Huhtanen et al., 2002). Mo 
et al. (2001) suggested that 1-propanol was negatively related to intake. However, the negative impact on intake of 1-propanol could not be confirmed in a later feeding trial (Mo et al., 2001). The close correlation between PA and 1-propanol could likely be explained by oxidation of 1-propanol to PA by yeast under aerobic conditions and/or the fermentation of 1,2-propanediol to PA and 1-propanol by certain species in isolated Lactobacillus strains in the initial stages of ensiling (Driehuis et al., 2001; Elferink et al., 2001). Propanol can also be produced by yeast in silage under anaerobic conditions (McDonald et al., 1991).

With background in this discussion, and in light of the results from the best combination procedure combined with the results of the JK method, and the empirical correlations to intake, the most descriptive variables of silage intake were: TA, PA, LA/TA, and TVFA. Excluding putrescine marginally lowered explained CV-validated variance to $71 \%$, with a slight increase in validated RMSE of 0.085 . The previously generated equation from this silage material (using simple and multiple linear regression) by Krizsan and Randby (2006) also only included volatile fatty acids (except acetic acid) and lactic acid. A validated variance of $73 \%$ in SDMI was explained with a validated RMSE of 0.100 . No quadratic elements of the variables were included in the present paper. Although there has been a strong focus on validation, the results should not be extrapolated and the interpretation should so far be restricted to this material due to the limited number of samples.

\section{Regulation of intake due to silage fermentation quality}

When separating the impact on intake due to palatability from preference as the modulation of intake when the feed is fed alone the differences between silage fermentation qualities may be less pronounced. This was well illustrated in the experiments conducted by Keady and Murphy (1997 and 1998). The same marked advantage for restrictively fermented silage could not be observed when the silages were offered one at a time. However, the intake data of silages treated with formic acid application were different from the inoculated and untreated silages (Keady and Murphy, 1998). The reductions in intake were observed with increases in $\mathrm{NH}_{3}-\mathrm{N}$, acetate, propionate, and a decrease in WSC. Even though the potential flavour compounds analysed in this study were mainly associated with silage of poor fermentation quality no reduction of intake could be deduced directly from them. They could possibly have been more important if short-term regulation of intake had been studied (i.e. meal size and frequency within the 1st day) or preference from a choice between feeds. This study indicated a differentiation between three fermentation qualities of silages in relation to intake: secondary fermented, extensively fermented, and silages displaying restricted lactic acid fermentation. It is suggested that by restricting the fermentation in low DM grass silages the potential intake of silage DM is maximised. This is in line with the results of Keady and Murphy (1998) and Shingfield et al.
(2002). Huhtanen et al. (2002) suggested that imbalanced nutrient supply on tissue level i.e. metabolic mechanisms are mainly responsible for the differences in intake between silage of different fermentation quality. However, metabolic mechanisms involved in the long-term regulation of intake of secondarily fermented silages have not been clearly separated from a possible effect of palatability.

\section{References}

Abrams SM, Harpster HW, Wangsness PJ, Shenk JS, Keck E and Rosenberger JL 1987. Use of a standard forage to reduce effects of animal variation on estimates of mean voluntary intake. Journal of Dairy Science 70, 1235-1240.

Choung JJ and Chamberlain DG 1993. Effects of addition of lactic acid and post ruminal supplementation with casein on the nutritional value of grass silage for milk production in dairy cows. Grass and Forage Science 48, 380-386.

Dawson L and Mayne CS 1995. The effect of either dietary additions or intraruminal infusion of amines and juice extracted from grass silage on the voluntary intake of steers offered grass silage. Animal Feed Science and Technology 56, 119-131.

Dawson LER and Mayne CS 1996. The effect of intraruminal infusions of amines and gamma amino butyric acid on rumen fermentation parameters and food intake of steers offered grass silage. Animal Feed Science and Technology 63, 35-49.

Dawson LER and Mayne CS 1997. The effect of infusion of putrescine and gamma amino butyric acid on the intake of steers offered grass silage containing three levels of lactic acid. Animal Feed Science and Technology 66 , 15-29.

Driehuis F, Elferink SJWH and Van Wikselaar PG 2001. Fermentation characteristics and aerobic stability of grass silage inoculated with Lactobacillus buchneri, with or without homofermentative lactic acid bacteria. Grass and Forage Science 56, 330-343.

Edward JJ 2003. A user's guide to principal components. John Wiley, Hoboken, NJ.

Elferink SJWH, Krooneman J, Gottschal JC, Spoelstra SF, Faber F and Driehuis $\mathrm{F} 2001$. Anaerobic conversion of lactic acid to acetic acid and 1,2-propanediol by Lactobacillus buchneri. Applied and Environmental Microbiology 67, 125-132.

Faverdin P, Richou B and Peyraud JL 1992. Effects of digestive infusions of volatile fatty-acids or glucose on food-intake in lactating or dry cows. Annales de Zootechnie 41, 93.

Henk M 1991. Volatile compounds in foods and beverages. Marcel Dekker, New York.

Hjorth JSU 1994. Computer intensive statistical methods: validation, model selection and bootstrap. Chapman \& Hall, London.

Huhtanen P 1993. Factors influencing forage intake. In Proceedings of the Nova Scotia Forage Council Symposium, Canada, pp. 103-127.

Huhtanen P 2003. Factors influencing on voluntary intake of silage-based diets, and the responses of silage quality in milk production. In Proceedings of the international symposium early harvested forage in milk and meat production, Norway, pp. 59-82.

Huhtanen P, Khalili H, Nousiainen JI, Rinne M, Jaakkola S, Heikkila T and Nousiainen J 2002. Prediction of the relative intake potential of grass silage by dairy cows. Livestock Production Science 73, 111-130.

Jaakkola S and Huhtanen P 1992. Rumen fermentation and microbial protein synthesis in cattle given intraruminal infusions of lactic acid with a grass silage based diet. Journal of Agricultural Science, Cambridge 119, 411-418.

Käppeli 0 1986. Regulation of carbon metabolism in Saccharomyces cerevisiae and related yeasts. Advances in Microbial Physiology 28, 181-209.

Keady TWJ and Murphy JJ 1997. The effects of treating low dry matter herbage with a bacterial inoculant or formic acid on the intake and performance of lactating dairy cattle. Animal Science 64, 25-36.

Keady TWJ and Murphy JJ 1998. A note on the preference for, and rate of intake of, grass silages by dairy cows. Irish Journal of Agricultural and Food Research 37, 87-91. 
Krizsan SJ and Randby ÅT 2006. The effect of fermentation quality on the voluntary intake of grass silage by growing steers fed silage as sole feed. Journal of Animal Science In press.

Langin D, Nguyen P, Dumon H and Malek A 1989. Aldehydes and ketones in silages: quantitative determination by high performance liquid chromatography. Annales de Recherches Vétérinaires 20, 119-127.

Lees GJ and Jago GR 1978. Role of acetaldehyde in metabolism - review. 1. Enzymes catalyzing reactions involving acetaldehyde. Journal of Dairy Science 61, 1205-1215.

McDonald P, Henderson AR and Heron SJE 1991. The biochemistry of silage, second edition. Chalcombe Publications, Marlow.

Martens $\mathrm{H}$ and Martens M 2000. Modified jack-knife estimation of parameter uncertainty in bilinear modelling by partial least squares regression (PLSR). Food Quality and Preference 11, 5-16.

Martens $\mathrm{H}$ and Martens M 2001. Multivariate analysis of quality: an introduction. John Wiley, Chichester.

Mbanya JN, Anil MH and Forbes JM 1993. The voluntary intake of hay and silage by lactating cows in response to ruminal infusion of acetate or propionate, or both, with or without distension of the rumen by a balloon. British Journal of Nutrition 69, 713-720.

Mertens DR 1994. Regulation of forage intake. In Forage quality, evaluation, and utilization. pp. 450-493 American Society of Agronomy, Inc., Crop Science Society of America, Inc., Soil Science Society of America, Inc., Madison, Wisconsin.
Mo M, Selmer-Olsen I, Randby ÅT, Aakre SE and Asmyhr A 2001. New fermentation products in grass silage and their effects on feed intake and milk taste. In Proceedings of the 10th international symposium on forage conservation, Brno, Czech Republic, pp. 98-99.

Mo M and Tjørnholm T 1978. Losses of carbon-containing substances during dry-matter determination by oven-drying. Acta Agriculturæ Scandinavica 28, 196-202.

Nørgaard Pedersen EJ 1967. Alkohol in ensilage (english abstract). Tidsskrift for planteavl 71, 355-358.

Peyraud JL, Widyobroto BP and Faverdin P 1993. Effects of addition of waterfilled bladders or volatile fatty acids into the rumen on digesta passage in the dairy cow eating ad libitum. Annales de Zootechnie 42, 187.

Rook AJ and Gill M 1990. Prediction of the voluntary intake of grass silages by beef cattle 1. Linear regression analyses. Animal Production 50, 425-438.

Shingfield KJ, Jaakkola S and Huhtanen P 2002. Effect of forage conservation method, concentrate level and propylene glycol on intake, feeding behaviour and milk production of dairy cows. Animal Science 74, 383-397.

Steen RWJ, Gordon FJ, Dawson LER, Park RS, Mayne CS, Agnew RE, Kilpatrick DJ and Porter MG 1998. Factors affecting the intake of grass silage by cattle and prediction of silage intake. Animal Science 66, 115-127.

Whitaker JR 1990. Microbial pectolytic enzymes. In Microbial enzymes and biotechnology (eds WM Fogarty and CT Kelly), pp. 133-176, Elsevier Applied Science, London. 